Boletín de la Sociedad Geológica Mexicana

VOLUMEN 63, NÚM. 3, 2011, P. 459-462

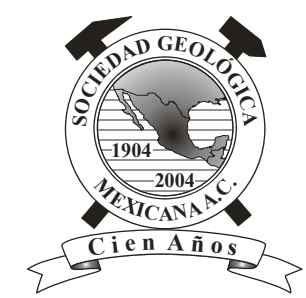

\title{
The first mandible fragment of Deinosuchus (Eusuchia: Alligatoroidea) discovered in Coahuila, Mexico
}

\author{
Héctor E. Rivera-Sylva $a^{1, *}$, Eberhard Frey ${ }^{2}$ \\ ${ }^{1}$ Departamento de Paleontología, Museo del Desierto, Prolongación Pérez Treviño 3745, 25015 Saltillo, Coahuila, México \\ ${ }^{2}$ Geowissenschaftliche Abteilung, Staatliches Museum für Naturkunde Karlsruhe, Karlsruhe, Alemania \\ *hrivera@museodeldesierto.org
}

\begin{abstract}
Here we report on the first mandible fragment of the giant alligatoroid eusuchian crocodyliform Deinosuchus found in Mexico. The specimen comes from Las Jicoteas locality, northwestern Coahuila. It was collected in 2007 by the first author. The fragment is from a left surangular, coming from the mandible of a Deinosuchus between six and seven metres in length.
\end{abstract}

Keywords: Deinosuchus, Alligatoroidea, Eusuchia, late Campanian, Coahuila, Mexico.

\section{Resumen}

Aqui reportamos sobre el primer fragmento craneal de aligatorido eusuchio crocodiliforme gigante Deinosuchus, que ha sido encontrado en México. El espécimen proviene de la localidad de Las Jicoteas, noroeste de Coahuila. Fue colectado en 2007 por el primer autor. El fragmento es un surangular izquierdo, de la mandíbula de un Deinosuchus el cual tendría una longitud de entre 6 y 7 metros.

Palabras clave: Deinosuchus, Alligatoroidea, Eusuchia, Campaniano tardío, Coahuila, México.

\section{Introduction}

Fossil remains of Mesozoic crocodyliforms are scarce in Mexico. Thalattosuchia has been reported from Late Jurassic marine sediments of Oaxaca (Ferrusquía and Comas, 1988), Puebla (Frey et al., 2002), Nuevo León (Buchy et al., 2006a; Velasco-Segura, 2007; Buchy, 2008) and Coahuila (Buchy et al., 2006b). From Cantera Tlayua (Albian, Early Cretaceous), Puebla, a crocodilian similar to the pholidosaurid Crocodileimus has been reported (Reynoso et al., 2000). Moreover, a few Late Cretaceous crocodyliforms have been discovered. From the San Carlos and Aguja formations, in Chihuahua, fossil remains assigned to Deinosuchus cf. D. riograndensis were described by Brown et al. (2004). Other crocodyliforms have been reported from Coahuila, including goniopholids and Brachychampsa from the Cerro del Pueblo Formation (Rodríguez-de la Rosa and Cevallos, 1998) and Deinosuchus riograndensis from the Aguja Formation (Rivera-Sylva et al., 2011).

Our understanding of fossil crocodyliforms in Mexico is still developing. Therefore, the description of newly discovered remains, no matter how small, is important to establish a database that later will allow reconstruction of the evolutionary history of those crocodyliforms that inhabited the area of today's Mexico.

The mandible fragment described here was recovered from a site located in the municipality of Ocampo, in the western part of Coahuila, close to the border with Chihuahua, $22 \mathrm{~km}$ northwest of the town of El Carricito 
(Figure 1).

\section{Geology}

The structural tectonics of northwest Coahuila consists of narrow anticlines and wide synclines. Both are affected by normal and lateral faults. Lateral faulting puts in discordant contact the marine sequence of limestones and mudstones containing lamellibranchs and abundant foraminifers that could correspond to the marine member of the Aguja Formation with the transitional sequence of sandstones, mudstones and siltstones, which correlate with the continental sequence where many dinosaur remains occur.

The Aguja Formation comprises mainly irregularly interbedded clay and sandstone, ranging from a few tens of millimetres to more than twelve metres in thickness. Beds of arenaceous and rudaceous, coquina sandstone, carbonaceous clay, lignite, and a rare fresh-water limestone appear in parts of the section. The formation is characterized by rapid vertical and lateral facies changes, as well as by a proportion of sand that is present in either the overlying or the underlying units (Hopkins, 1965).

Based on the colour variation of the clay, the formation is roughly divided into three parts. The basal part consists of a grey-green clay, which weathers to a buff-yellow colour, and resembles the clays of the underlying Pen Formation. The clay of central part is green with some buff-yellow beds. In the top part, the clay shows a melange of pale maroons, greens, blue-blacks, and reds much resembling the clay in the overlying Javelina Formation. The change in clay colour probably correlates with a change from open water marine conditions, through intertidal marine, brackish and fresh water conditions with terrestrial conditions in the centre of the formation, where lignites and carbonaceous clay form the dominant lithology. This lithology also occurs throughout the lower part of the Aguja Formation.

Hopkins (1965) recognised oscillating marine transgressions in the Aguja Formation alternating with non-marine episodes as the result of local intermittent delta progression, and subsequent subsidence due to the compaction of the underlying clays.

The system was deltaic with a narrow pro-delta seam with marshes, oxbows, and near shore lagoons with sandy or silty bars (Hopkins, 1965; Weide et al., 1972; Lehman, 1982).

\section{Systematic palaeontology}

Crocodyliformes Benton and Clark, 1988

Eusuchia Huxley, 1875

Alligatoroidea Gray, 1844

Deinosuchus Holland, 1909

\section{Deinosuchus indet.}

3.1. Material. Fragmentary left surangular of Deinosuchus (Figure 2A-C), which is housed in the Museo del Desierto, Saltillo, Coahuila, Mexico under the collection number CPC 485 (CPC: Colección Paleontológica de Coahuila).
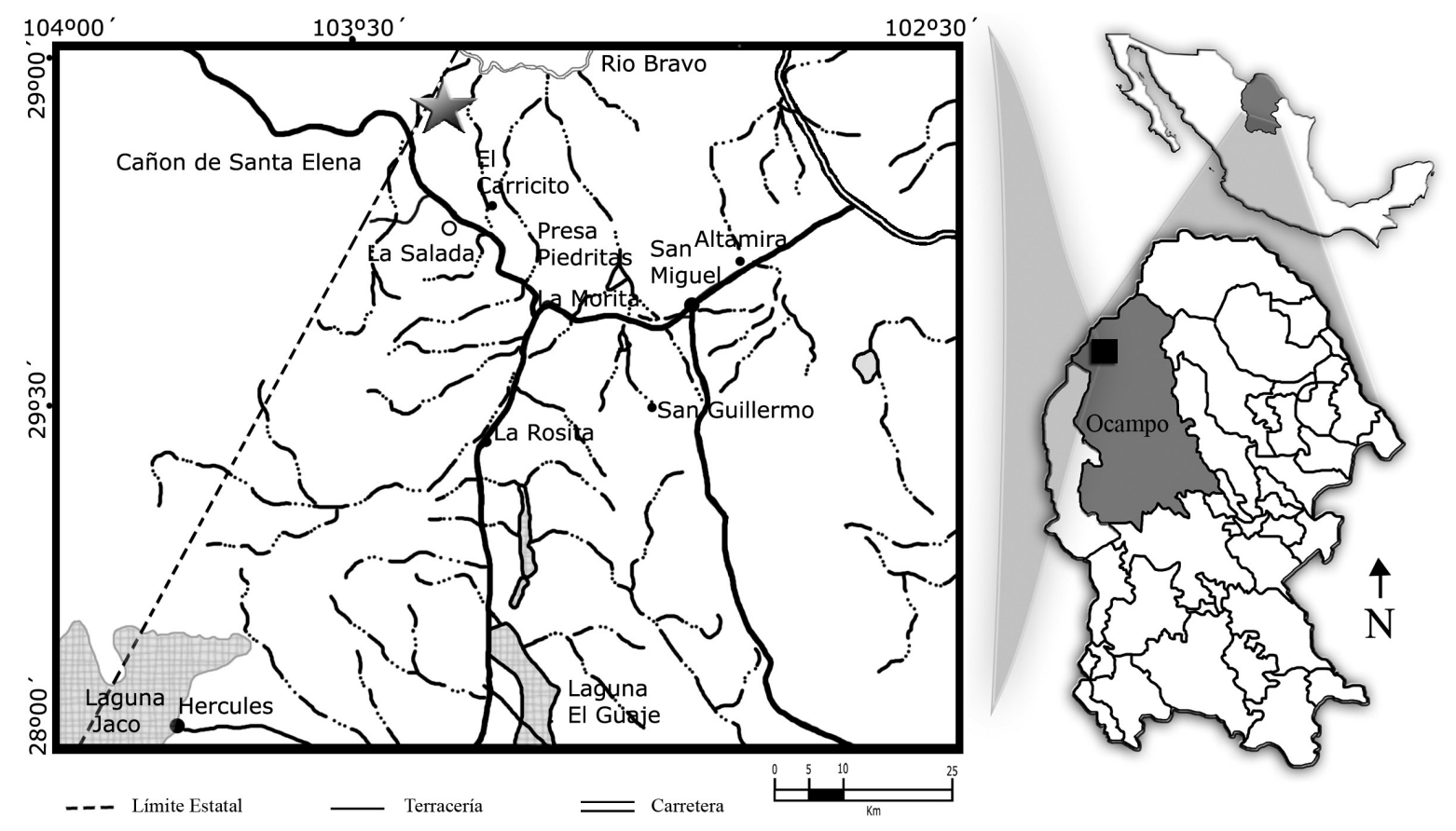

Figure 1. Geographical map of the locality 
3.2. Horizon and Locality. The material was recovered from the upper member of the Aguja Formation (Upper Cretaceous, Campanian), west of the El Carricito, Township of Ocampo, Coahuila, Mexico.

3.3 Preservation. The bone is uncrushed, but the rostal and caudal margin show sub-vertical breaks, exposing spongiosa encased by a dense compacta. The specimen was broken horizontally in two halves of approximately the same size, which were glued together (Figure 2A, B).

3.4 Description. The fragment is identified as coming from a left surangular based on a smooth, slightly convex dorsal surface that would normally occur immediately rostral to the mandibular glenoid fossa (Figure 3). This surface is an elongate oval three times as long as wide in the preserved portion (Figure $2 \mathrm{C}, \mathrm{C}^{\prime}$ ). This is the insertion place of the caudal-most portion of $\mathrm{m}$. adductor mandibulae externus superficialis (Holliday and Wittmer, 2007) and
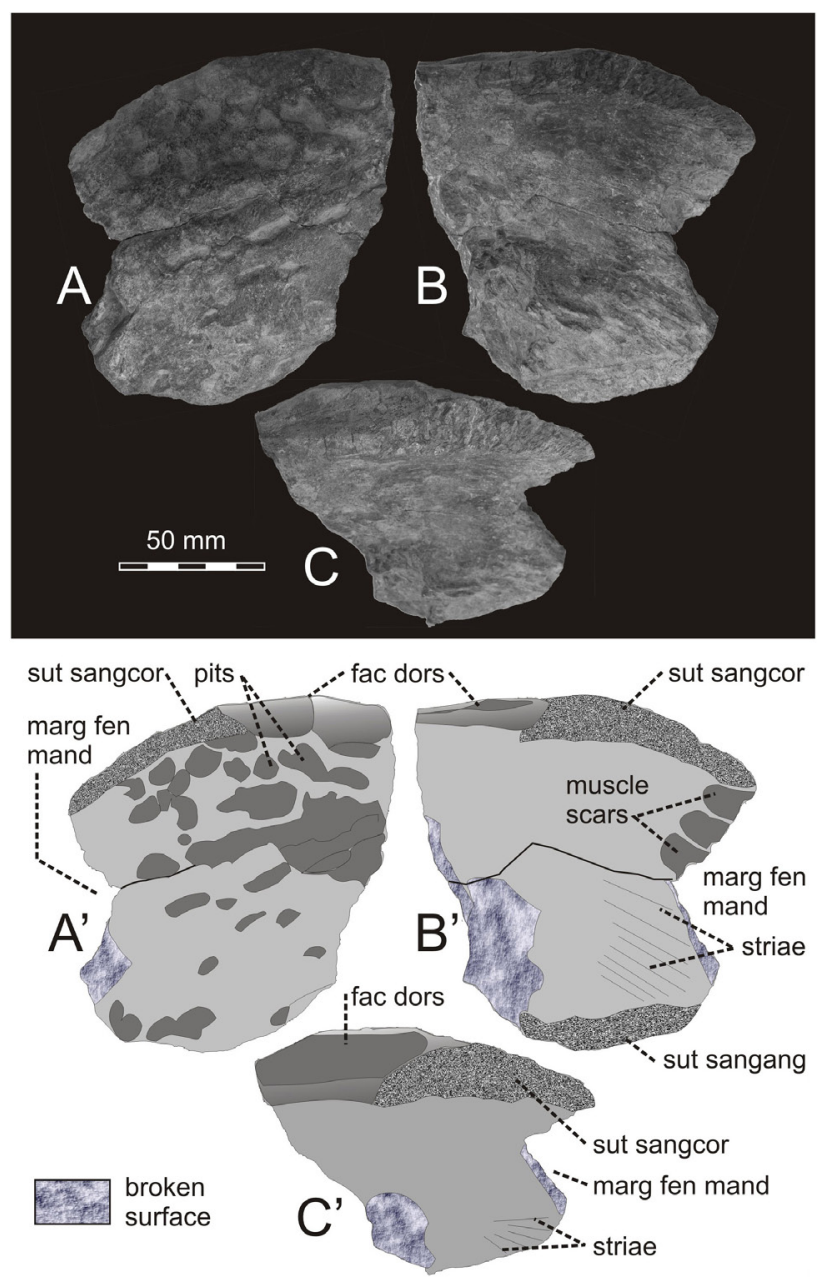

Figure 2. Fragment of a left surangular; A) external view, B) internal view, C) dorsal view. Abbreviations: fac dors = facies dorsalis, marg fen mand $=$ margo fenestrae mandibularis, sut sangang = sutura suranguloangularis, sut sangcor $=$ sutura surangulocoronoidea. has the typical morphology for eusuchian crocodyliforms. The transversely striated, rugose face of the surangularcoracoid suture, where the caudal process of the coronoid contacted the surangular, lies rostrally (Figure $2 \mathrm{~A}, \mathrm{~A}^{\prime}$ ). The rostral process that formed the caudodorsal margin of the mandibular fenestra has broken off, as has the entire caudal part of the bone (Figure 3).

The external face is deeply and irregularly pitted. The dorsolateral margin is slightly bulged, where the lateral fibres of $\mathrm{m}$. adductor mandibulae externus superficialis inserted (Figure 2A, A'). The internal face shows a faint horizontal sub-parallel striation in its dorsal half and a pronounced caudally radiating striation in its ventral half. In the caudoventral third a breakage with the spongiosa is exposed (Figure 2B, $\mathrm{B}^{\prime}$ ). Adjacent to the cranial margin of the bone there are three depressions with rounded cranial margins and longitudinal dorsal and ventral margins running parallel to each other (Figure 2B, $\mathrm{B}^{\prime}$ ). The bone wall tapers from a thickness of approximately 25 millimetres cranially to a 2 millimetre thick edge that formed the caudal margin of the mandibular fenestra. Both striae and depressions from the insertion place of m. pterygoideus dorsalis (Holliday and Wittmer, 2007) are deduced from their orientation on the internal surface of the surangular (Figure 2B, B').

The caudoventral face of the surangular represents the cranial-most portion of the surangular angular suture, which as a rugose, has a slightly transversally-striated structure (Figure 2 B, B'). The cranionventral portion of the bone is missing (Figure 3).

3.5 Comments. Previously discovered specimens of Deinosuchus in Mexico come from the Late Cretaceous (Campanian) of Chihuahua (Westgate et al., 2002; Brown et al., 2004).

The specimens from Coahuila are likely conspecific with Deinosuchus (Phobosuchus) riograndensis, which is known from the Aguja Formation, Big Bend National Park, Texas (Colbert and Bird, 1954; Schwimmer, 2010).

The specimen presented here is the fragment of a left surangular (Figure 2), which is diagnosed as coming from Deinosuchus by its coarse and irregular pitting on its external much resembling that of the osteoderms and its massiveness (Colbert and Bird, 1954). Identification beyond genus level is not possible based on the given material, despite the likelihood that the material comes from $D$. riograndensis (Schwimmer, 2010).

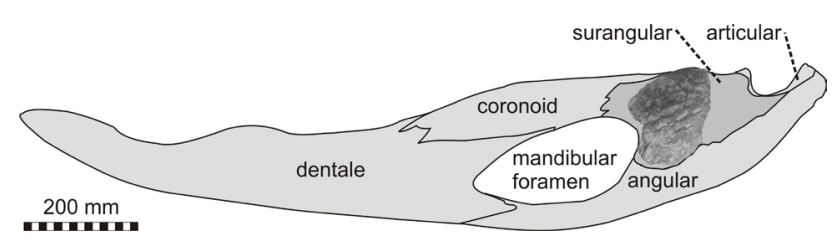

Figure 3. Fragment of the left surangular in the osteological context of the mandible of Alligator mississippiensis, traced from an original skull. Note the close match of the fragment and the reconstructed size. 


\section{Discussion}

Cranial remains of Deinosuchus are generally sparse in the fossil record and only comprise fragments. The fragments which were used by Colbert and Bird (1954) to reconstruct the Deinosuchus skull formerly on display at the American Museum of Natural History in New York refer to the most complete cranial material of Deinosuchus discovered to date. This skull reconstruction is based on that of a modern Cuban crocodile (Crocodylus rhombifer). The American Museum specimen preserves a portion of the left surangular that does not reach the mandibular fenestra. We superimposed the surangular fragment described here onto the mandible of an American Alligator (Alligator mississippiensis) and found a perfect match including the direction and distance of the sutures with the coronoid and the angular (Figure 3). Scaling the bone up based on the skull of A. mississippiensis, the skull of the Deinosuchus, to which the articular belonged, had a length between 0.9 and $1.0 \mathrm{~m}$. For the entire animal this would have meant a total length of 6.5 to $7 \mathrm{~m}$, a predator that certainly attacked medium-sized dinosaurs as is evidenced by bite marks in dinosaur bones (Rivera-Sylva et al., 2009).

\section{Acknowledgements}

We would like to thank the following individuals for their contribution to this project: Ileana de la Peña, Elizabeth Jardón, and Rubén Guzmán for their help during the field season. Jorge Ortiz Mendieta is thanked for illustrating the locality map. The Museo del Desierto is also thanked for supporting this investigation. In the same manner we wish to thank Francisco Palomino from INEGI (now retired). We cordially thank David R. Schwimmer (Columbus State University) and Christopher Brochu (University of Iowa) for their constructive and very helpful comments. They substantially enhanced the manuscript.

\section{References}

Benton, M.J., Clark, J.M., 1988, Archosaur phylogeny and relationships of the Crocodylia, in Benton, M.J. (ed.), The phylogeny and classification of the Tetrapods Vol. 1: Oxford, U.K., Clarendon Press, 295-338.

Brown, R.B., Westgate, J.W., Cope, D.A., 2004, Primer registro del cocodrilo gigante Deinosuchus cf. riograndensis en México (resumen), in IX Congreso Nacional de Paleontología: Tuxtla Guiérrez, Chiapas, México, Sociedad Mexicana de Paleontología, 25.

Buchy, M.C., 2008, Reevaluation of the holotype of Plesiosaurus (Polyptychodon) mexicanus Wieland, 1910 from the ?Upper Jurassic of Mexico: a talattosuchian, not a sauropterygian: Revista Mexicana de Ciencias Geológicas, 25, 517-522.

Buchy, M.C., Frey, E., Stinnesbeck, W., González González, A.H., 2006b, A new Tithonian (Upper Jurassic) marine vertebrate concentration Lagerstätte in north-eastern Mexico: Hantkeniana, 5, 17-19.
Buchy, M.C., Vignaud, P., Frey, E., Stinnesbeck, W., González González, A.H., 2006a, A new thalattosuchian crocodyliform from the Tithonian (Upper Jurassic) of northeastern Mexico: Comptes Rendus Paleovol, 5, 785-794.

Colbert, E.C., Bird, R.T., 1954, A gigantic crocodile from the Upper Cretaceous beds of Texas: American Museum of Natural History Novitates, 1688, $22 \mathrm{p}$.

Ferrusquía, I., Comas, O., 1988, Reptiles marinos mesozoicos en el Sureste de México y su significación geológico-paleontológica: Revista del Instituto de Geología UNAM, 7, 168-181.

Frey, E., Buchy, M.C., Stinnesbeck, W., López-Oliva, J.G., 2002, Geosaurus vignaudi $\mathrm{n} . \mathrm{sp}$. (Crocodyliformes: Thalattosuchia), first evidence of metriorhynchid crocodilians in the Late Jurassic (Tithonian) of central-east Mexico (State of Puebla): Canadian Journal of Earth Sciences, 39, 1467-1483.

Gray, J.E., 1844, Catalogue of Tortoises, Crocodilians, and Amphisbaenians in the Collection of the British Museum: British Museum (Natural History), London, 8, 8.

Holland, W.J., 1909, Deinosuchus hatcheri, a new genus and species of crocodile from the Judith River beds of Montana: Annals of the Carnegie Museum, 6, 281-294.

Holliday, C.M., Wittmer, L.M., 2007, Archosaur adductor chamber evolution: integration of musculoskeletal and topological criteria in jaw muscle homology: Journal of Morphology, 268, 457-484.

Hopkins, E.M., 1965, Sedimentology of the Aguja Formation, Big Bend National Park, Brewster County, Texas: Austin, Texas, The University of Texas at Austin, master thesis, $165 \mathrm{p}$.

Huxley, T.H., 1875, On Stagonolepis robertsoni, and on the evolution of the Crocodilia, Q.: Journal of the Geological Society, 31, 423-438.

Lehman, T.L., 1982, A ceratopsian bone bed from the Aguja Formation (Upper Cretaceous), Big Bend National Park, Texas: Austin, Texas, The University of Texas at Austin, master thesis, 209 p.

Reynoso, V.H., Cabral Perdomo, M.A., Clark, J.M., 2000, The reptiles of the Tlayúa Formation, in Espinosa-Arrubarrena, L., MontellanoBallesteros, M., Applegate, S.P., (eds.), Guide Book of the Field Trips of the $60^{\text {th }}$ Meeting of the Society of Vertebrate Paleontology: Avances en investigación, Universidad Autónoma del Estado de Hidalgo Special Publication, 106-110.

Rivera-Sylva, H.E., Frey, E., Guzmán-Gutiérrez, R., 2009, Evidence of predation on the vertebra of a hadrosaurid dinosaur from the Late Cretaceous (Campanian) of Coahuila, Mexico (letter): Carnets de Géologie/Notebooks on Geology, 2, 1-6.

Rivera-Sylva, H.E., Frey, E., Guzmán-Gutiérrez, R., Palomino-Sánchez, F., Stinnesbeck, W., A., 2011, Deinosuchus riograndensis (Eusuchia: Alligatoroidea) from Coahuila, Mexico: Revista Mexicana de Ciencias Geológicas, 28, 267-274.

Rodríguez-de la Rosa, R.A., Cevallos-Ferrís, S.R.S., 1998, Vertebrates from the El Pelillal locality (Campanian, Cerro del Pueblo Formation), southeastern Coahuila, Mexico: Journal of Vertebrate Paleontology, $18,751-764$

Schwimmer, D.R., 2010, One or two species of the giant crocodylian Deinosuchus?: Journal of Vertebrate Paleontology, $30,161 \mathrm{~A}$.

Velazco Segura, J., 2007, Cocodrilos marinos del Jurásico tardío de la formación La Casita en Coahuila y Nuevo León, México: Linares, Universidad Autónoma de Nuevo León, master thesis, 105 p.

Weide A.E., Wolleben J.A., McBride E.F., 1972, Late Cretaceous depositional systems in northeastern Mexico: Gulf Coast Association of Geological Societies Transactions, 22, 323-329.

Westgate, J., Pittman, J., Brown, R.B., Cope, D., 2002, Continued Excavation of the first dinosaur community from Chihuahua, Mexico: Journal of Vertebrate Paleontology, 26, 138A.

Manuscript received: February 25, 2009.

Corrected manuscript received: April 15, 2009.

Manuscript accepted: June 15, 2009. 